\title{
Bridging the contradictions of social constructionism and psychoanalysis in a study of workplace emotions in India
}

This article is forthcoming in the journal Culture and Organization - accepted 2015 December Eda Ulus and Yiannis Gabriel

\begin{abstract}
This article makes a contribution to the study of emotions in organizations by offering a systematic juxtaposition and cross-fertilization of psychoanalytic and social constructionist approaches. These two traditions have found it hard to communicate in the past when addressing organizational emotions. Points of similarity and tension between them are discussed in connection with two critical case studies of female Indian managers discussing their emotions at the workplace. These were obtained during field work in which emotions were studied through narratives generated by a free-association interview approach. Both the emotions described in the narratives themselves and the emotions of the interview encounter were analysed, as resources for a rapprochement of contrasting perspectives on emotion. This rapprochement acknowledges the psychoanalytic emphasis on unconscious dynamics shaping the emotional lives of individuals and groups, while also honouring the social constructionist emphasis on how emotions are influenced by social, cultural and discursive practices.
\end{abstract}

Keywords: emotions; India; social constructionism; psychoanalysis; stories; postcolonial context 


\section{Introduction}

The plump, humble elephant god, Lord Ganesh, is the Hindu god of beginnings and of knowledge; he is also the remover of obstacles. In the spirit of Ganeshji, the suffix ji being an address of respect, this article offers a juxtaposition of psychoanalytic and social constructionist approaches to emotion and proposes several possibilities of cross-fertilization. Crossing theoretical boundaries involves numerous obstacles, not only academic ones such as diverging assumptions and emphases, but also emotional obstacles, such as mistrust, fear, and envy, which afflict academic traditions when facing others that proceed from different assumptions. By adopting novel ways of confronting these tensions and by allowing an acceptance of some degree of contradiction, many of these barriers can be overcome, as we will seek to show, learning from fieldwork in India.

The paper's main contribution is to demonstrate unique insights into the study of workplace emotion, resulting from a systematic interweaving of social constructionism and psychoanalysis. The study of emotions in organizations has received attention from a wide range of approaches and perspectives. In this paper, we focus on two qualitative approaches to the study of organizational emotions, social constructionism and psychoanalysis, which have offered powerful insights, but which have remained relatively apart from each other. As Fineman (2000) noted, many investigations of emotion at work are undertaken from social constructionist perspectives. A greater engagement with psychoanalysis, we argue, adds rich possibilities of interpreting the diverse meanings and effects of workplace emotion.

This paper demonstrates that the study of culture-specific emotional dynamics in India helps to expand social constructionist research on emotion but also supports the deployment of psychoanalytic concepts across cultures. The empirical material in this study comes from 
fieldwork with employees in the Delhi area, in large part relying on their stories and free associations about their emotional experiences at the workplace. These narratives enabled us to observe and reflect on the respondents' emotional displays while reliving their experiences. Thus, in addition to the emotions described in the narratives, we were able to examine the participants' actual emotional performances during interviews and the emotion rules governing these interviews.

The paper is structured in the following manner. Key features of specific social constructionist and psychoanalytic approaches to emotion are presented, highlighting points of tension and potential cross-fertilization. Next, the relevance of India for this endeavour is discussed, arguing that India offers a corrective to numerous studies drawn from Western cultures that tacitly accept Western emotion rules and dynamics. The paper then focuses on two contrasted case studies. The first addresses gender and spirituality, highlighting a disconnection between overtly expressed and tacitly communicated emotions. The second revolves around a traumatic experience described metaphorically as a nightmare, which unleashes emotions that are normally disavowed or repressed. Not only the emotional content of the second case but also the emotional dynamics of the interview itself offer a sharp juxtaposition to the earlier one, enabling us to draw psychoanalytic and social constructionist approaches closer together in a crossfertilization of the two approaches. ${ }^{1}$

\section{Social constructionist and psychoanalytic approaches to emotion}

\footnotetext{
${ }^{1}$ Throughout our discussion, we use the first person plural to describe our positions as authors. When discussing the first author's direct experiences and reflections in the field, we switch to first person singular acknowledging their personal and subjective qualities.
} 
Berger and Luckmann (1967) set the stage for a social constructionist conceptualization of emotion as that which is created by the social world and the roles that we inhabit. References to emotions include the example of a judge who needs to be aware of his (sic) emotions, but also control them, which implies subordination of emotions to conscious, cognitive controls (1967, 94). Since the publication of this classic text, social constructionism has come to encompass a diversity of approaches. Acknowledging this diversity, Cromby and Nightingale (1999) note shared areas of emphasis in social constructionist understanding, including the shaping of people's lives by social processes, particularly through language. Within this social constructionist framework, then, emotions are 'cultural phenomena whose meaning emerges through culture, is communicated through culture, and is even generated by culture' (Gabriel, 1998b, 295). More recently, a number of authors from the social constructionist perspective have looked at how social emotions are reproduced at the broader cultural level through a variety of historically specific narratives, called 'emotionologies, society's "take" ' (Fineman, 2010, 27) on how emotions should be experienced and expressed towards particular groups and institutions.

Social constructionist perspectives on emotion agree that emotions are culturally acquired and constructed through the medium of language and available for conscious appraisal. A fundamental concept of these perspectives is emotional labour, which stresses how feeling rules, arising from social contexts, impose restrictions upon the experience and expression of emotion (Hochschild, 2003). The driving forces of emotional labour are the systematic attempts of organizations to control and exploit their employees' emotional resources in order to enhance performance. Human feeling, in Hochschild's original conceptualization, becomes commercialised, part of what an organization sells to its customers. The metaphor of performance (originally found in Goffman (1959) is used in connection with emotional labour, 
since acting, deep or surface, is frequently required to meet an organization's emotional demands.

Hochschild's contribution has been highly influential in the study of emotions in organizations; however, numerous scholars have argued for the need to expand and update her conceptualization (e.g. Vogler, 2000; Theodosius, 2008). Bolton (2005) has noted that people at work often engage emotionally in ways that are not directly tied to formal job requirements (developing supportive relationships with co-workers or customers out of personal choice). Korczynski (2003) has referred to groups of employees forming supportive emotional relationships as 'communities of coping'. Other scholars have noted that emotional labour itself is culturally specific (Das et al., 2008), and different cultures draw the line between genuine and artificial emotional performances very differently (e.g. Bozionelos and Kiamou, 2008). Culture is intimately tied to the way emotional labour is understood - not only in specifying emotion rules appropriate to different situations, but also in stipulating what counts as an emotion rule and what constitutes emotional hypocrisy.

Psychoanalytic perspectives tend to stress the pre-linguistic and anti-cultural quality of at least some emotions and argue that emotional labour can be unconscious as well as conscious (see, for example, Craib, 1997; Gabriel, 1998b; Gabriel, 1999). Looking at the emotional labour of those engaged in caring for others, Gabriel (2009) illustrates the ambivalence of the emotional experiences of both the carer and the cared for, which may arise from unconscious fantasies of dependency, power, and vulnerability. It is this emphasis on unconscious factors and their origin in early childhood which marks psychoanalytic approaches to emotion, every bit as decisively as emphasis on language and culture marks social constructionist ones. Psychoanalysis does not 
dismiss culture as a shaper of emotion, but instead emphasises the shared rituals and ceremonies, as well as the shared myths and narratives, which give a collective voice to emotions.

Childhood is seen by psychoanalytic theorists as a period when unconscious patterns of relating with significant others form, which in turn influence expectations of adult relationships (Frosh et al., 2003; Freud, A., 1966; Kakar, 2008). The term 'transference' (Czander, 1993) refers to the process in which people transfer onto others emotional expectations that arose in earlier interactions with a significant caregiver(s). People on the receiving end of transference respond with what is called countertransference (Stein, 2004). To illustrate, a student who relates to a female academic as a mother figure transfers expectations onto her about what emotions and behaviours will be received in return; the academic, for her part, will experience a countertransferential response to this process. She may, for example, unconsciously indulge in this mother fantasy, or she may reject it and react with denial of, distancing from, or resentment towards the student's transference. Countertransference may be considered as the psychoanalytic approach to reflexivity. A key feature of countertransference is a constant and vigilant reflection about one's own emotional responses and behaviours and their possible unconscious motives during an encounter with another person. Throughout this research, I worked intensively with my own countertransference by reflecting continuously on my emotional responses to my interviewees. This process helped me realize the significant impact that my own longstanding unconscious expectations and desires were having on my emotional exchanges with my Indian respondents. Transference and countertransference are an intricate, delicate dance of mutually affecting emotions between individuals that often occurs under the surface of explicit emotion rules, or even in reaction to or rejection of these rules. 
Psychoanalytic approaches diverge on a number of issues, but they share an emphasis on how emotions are shaped and transformed by unconscious defences, deployed to offset psychological discomfort (e.g. Freud, A., 1966). In defensive processes, threatening experiences, including emotions, are distorted in an attempt to ease anxieties; for example, feelings of nostalgia may be the result of a defence against disillusionment with the present. Defences may be adaptive, enabling us to cope with uncertainties and disappointments, but may exacerbate underlying conflicts or backfire altogether. Culture offers people collective defences and collective consolations for the different troubles and frustrations that they encounter.

A fundamental tension between these social constructionist and psychoanalytic conceptualisations of emotions is that the former approaches them as consciously constructed and cognitively worked through phenomena, while the latter sees them as bound up with fantasies and transformed through unconscious defences. Consciously learned emotion rules about cultural demands may be resisted unconsciously. Emotion rules may be followed, not to meet the conscious expectations of an organizational other, but rather to satisfy one's own unconscious desires or fantasies. In spite of these differences, psychoanalytic and social constructionist approaches to workplace emotions share many similarities (Gough 2004; Clarke 2003; Frosh 2001, 2003) including an acknowledgment of emotion as a core motivational force, a recognition that emotion and cognition interpenetrate in many ways, and an engagement with emotion as a starting point for interpreting social and organizational dynamics (Fineman, 2000, 2004; Gabriel and Griffiths, 2002). Both perspectives acknowledge the importance of culture in shaping emotions, although a psychoanalytic one places greater emphasis on the controlling, consoling, and narcissistic aspects of culture, such as its function of providing an individual 
sense of self-importance and belonging, while a social constructionist approach places greater emphasis on culture's meaning-making functions.

Psychoanalytic and social constructionist approaches to emotion both have their weak spots - psychoanalysis tends to underplay the social dimensions of emotions (why, for example, specific social occasions like interviews trigger specific emotions), and is reluctant to recognize the numerous ways in which emotions interact with, rather than oppose, cognitive processes. Social constructionist theories, for their part, tend to lose sight of the sheer irrationality of certain emotions, their overwhelming ability to influence actions in self-defeating ways, their ultimate origin, and their mobile, transforming nature. Fineman $(2000,2003)$, an eminent social constructionist authority, juxtaposes emotion, the socially constructed and culturally displayed dimension of affect, to 'feeling', its personal, private dimension. In funerals, for example, emotion rules dictate public displays of grief, which vary across different cultural settings. These may or may not reflect the feelings of a person crying publicly to satisfy a socially constructed emotion rule, but who may privately feel no sadness. In a different culture where public crying is unacceptable, a mourner may display emotions of calm acceptance while privately experiencing intense anguish.

Offering a neat procedure to bring together these perspectives is not the goal of this paper. Contradictions between theoretical perspectives cannot be ironed out through forced formulaic 'reconciliations'. Instead, our approach aims at a theoretical interweaving of the two approaches when addressing empirical material, similar to Prasad $(2014,234)$ who '.. draws upon an intricate combination of psychoanalytic and postcolonial thought' in his analysis of work experiences at a neo-colonial site. Like Prasad, we aim to demonstrate the critical possibilities that arise from such a theoretical interweaving, drawing on both the politico- 
ideological resources afforded by the constructionist concept of emotionology (Fineman, 2010) and the critical potential of the central unifying concept of psychoanalysis, the unconscious (Gabriel, 1999). In this way, we hope to demonstrate that contradictions are not stumbling blocks to a critical discussion of emotion at the workplace ${ }^{2}$. To this end, field material from India will be analysed to show that cross-fertilisation of ideas from these frameworks does not require the ironing out of theoretical tensions, nor does it have to violate the core assumptions of each perspective. As Fineman argued, ‘emotion's potential multifacetedness suggests that any one approach to understanding "it” will be just that - one approach' $(2004,721)$. This paper will demonstrate the critical potential of studying emotion from more than one approach.

\section{India as a terrain for intertwining social constructionist and psychoanalytic perspectives on} emotion

Workplace emotions in Eastern cultures have not been widely studied or understood. Despite their emphasis on culture and language as shapers of emotion, social constructionist studies have focused heavily on Western organizational contexts. India offers a terrain of immense linguistic and religious diversity and rich cultural and intellectual heritage, alongside a history of foreign occupation and colonial oppression, creating emotional landscapes that are both strikingly different from, and also remarkably similar to, those of Western cultures. Thus, emotion rules governing relations between superiors and subordinates or 'insiders' and 'outsiders' (including researchers and their respondents) can be markedly different. The social

\footnotetext{
${ }^{2}$ We are keenly aware that the empirical material we shall be presenting may be approached in many different ways, along different traditions that have addressed emotion, including identity theory, postcolonial theory, political theory as well as different psychoanalytic or social constructionist schools. In line with the aim of this paper expressed in the title, our ambition is to demonstrate the critical possibilities that are generated from a juxtaposition of psychoanalytic and social constructionist perspectives, and our focus will remain on these two.
} 
constructionist framework provides many resources for understanding the historically distinctive Indian workplace cultures and so too do psychoanalytic perspectives. Sudhir Kakar (1971a), India's pre-eminent psychoanalyst, notes that the colonial dynamic of British ruler and Indian worker extensively dehumanised the subordinates, leading to an authoritarian ethos in many Indian organizations. Stories in Indian textbooks indicate that emotions to a greater extent than instrumentality are central to authority relations, with authority figures 'modelled on... the paternal image of assertion and control... or the maternal image of nurturance and support' (Kakar, 1971b, 96). The enduring legacy of colonial authoritarianism and the longstanding Indian traditional familial authority find expressions in many Indian work organizations, shaping emotion rules and expectations at work, including emotions displayed towards foreign researchers. In postcolonial times British-Indian emotional dynamics can be reproduced in relations between Indian superiors and subordinates, and can trigger off anxieties when acted out in the presence of 'white' managers or visitors (see Kakar 1971a and Nandy 1982) ${ }^{3}$.

My status as a foreign researcher in India cannot be overlooked, as it directly affected the ways in which emotions were discussed, displayed and controlled. As becomes clear in the analysis that follows, it provided a vital resource for contrasting psychoanalytic and social constructionist approaches to emotion. The relationship between myself and my interviewees took on new meanings in a postcolonial context. From a social constructionist perspective, I embodied multiple roles related to gender, foreign status, and profession, which will be probed for their effects on the interviewees' emotions; from a psychoanalytic perspective, I triggered off

\footnotetext{
${ }^{3}$ The history of psychoanalysis in India provides, in itself, a rich resource for illustrating interlocking bonds between socially constructed and unconscious dynamics of emotion. In his correspondence with Sigmund Freud, Girindrasekhar Bose, who initiated psychoanalysis in India, suggested that castration anxiety, an unconscious phenomenon in European male patients, surfaces in Indian male patients as a desire to be female (Sinha, 1966). Bose's observation suggests that anxiety is universal, but with culturally specific expressions (Kakar, 2008).
} 
specific types of transference and countertransference. The emotions of the research encounter itself constitute a vital part of the empirical material and crucial resource in drawing closer the two perspectives.

\section{Methodology}

In 2009, I conducted a field study in Delhi and satellite cities, such as Faridabad, Gurgaon, and Noida, to examine how Indian employees describe and express their work-related emotions and to evaluate various social and unconscious forces shaping their experiences. The interviewees were university-educated, fluent in English and had been exposed to Western culture. ${ }^{4}$ This paper focuses on interviews with two female managers in a transportation business, both Hindu and in their late twenties, referred to as 'Sonal' and 'Rekha'. Sonal, a finance manager, and Rekha, an internal audit and control manager, were part of the wider project on studying emotion and are discussed here because they offer very contrasting approaches to emotion management, in spite of having access to the same organizational and linguistic symbols and resources. This approach is consistent with both psychoanalytic and social constructionist methodologies which often focus on a relatively narrow range of data, submitting them to close scrutiny rather than addressing broad regularities across a wide range. My interactions with Sonal and Rekha were very different emotional experiences, providing me with an additional opportunity to study the emotion rules and transferential dynamics of the

\footnotetext{
${ }^{4}$ As language is paramount to social constructionist interpretation, expressions in native Indian languages may have revealed more closely people's sensemaking. It is notable, however, that 'English is a commonly used business language in India' (Mellahi et al, 2010, 355) thus shaping how workplace emotions are constructed, experienced, and conveyed.
} 
interviews themselves, and offering another layer of analysis for interweaving social constructionist and psychoanalytic approaches.

The experiences discussed in these two interviews addressed several emotionally charged aspects of work experiences of Indian elites - gender tensions, colonial dynamics, and fears of recession-induced redundancy - providing good opportunities for interpretation from more than one theoretical angle. These experiences demonstrate how local, historical dimensions of workplace emotion intersect with current globalizing dynamics. Social constructionist insights provide valuable analytic tools for understanding expected emotion expressions, which may be the outcome of explicit and implicit emotion rules linked to one's organizational role, while psychoanalysis provides a complementary framework for analysing the lived emotional responses to these expectations.

In focusing on a relatively small number of incidents drawn from a much broader range of empirical material, our methodology is consistent with wide-ranging practice in qualitative research that seeks to delve in depth into an individual's experiences rather than generalising from the experiences of several individuals (see, for example, Muhr, 2012, Muhr and Kirkegaard, 2013 and Koch, 2013). The interviews themselves invited respondents to talk about their emotional experiences at work through a list of possible questions prepared in advance with social constructionist and psychoanalytic considerations in mind. Some of these questions were phrased so that responses could later be analysed utilising the constructs of these perspectives: for example, 'Did you experience a time at work, when you felt one way inside, but you couldn't show your feelings to others?'. This approach, known as free association interviewing, is advocated by Hollway and Jefferson (2000) who argue that, in contrast to structured interviews, free association interviews pursue meaning as their primary objective by creating a space for 
respondents to share their own sensemaking. This technique proved suitable for generating material about emotion that could then be interpreted from different theoretical perspectives. During the interviews, certain questions were selected from the list, but new questions were also raised to accommodate the path that an interviewee had chosen to take. Answers to these questions offered insights into the dynamic of the interview encounter itself, as well as contextual work details, which enhanced confidence in our interpretations from both psychoanalytic and social constructionist perspectives. The interviews were thus partly structured. The structured aspect included questions aimed at testing significant assumptions implicit in the two theoretical outlooks on emotion. Much of the actual interview exchange, on the other hand, was unstructured and spontaneous, in response to the meanings shared by the respondent.

Unlike semi-structured interviews, free-association interviews do not discourage respondents from going off the path from the prepared questions. A response that appears disconnected or whimsical may represent a surfacing of an individual's unconscious desire, triggered by the interview interaction. The free-association interview often evokes a clinical psychoanalytic setting in which the interviewer listens for extended periods of time with minimal prompting or responding. Yet, there are significant differences between clinical and research interviews, the former driven by a therapeutic concern for the patient's recovery, the latter by a scientific concern to establish meaningful understanding (e.g. Kvale, 1999).

An important feature of the field material was stories and other narratives. Gabriel (2000) argues that stories offer both a way of retrospectively making sense of experiences and reengaging with some of the original emotions experienced by the storyteller. In particular, stories provide freedom to the teller to communicate emotions and invite the researcher to enter the 
emotional tone of the experience. When an individual tells a story, she/he can reveal many facets of emotion at work, thus enabling researchers to examine the motivation for telling the story, the overt as well as the implicit emotions residing in the narrative, the emotions communicated by the narrator in telling the story, and the listener's own emotional responses to the narrative (Gabriel, 1991). During the interviews, participants were explicitly invited to share any stories about their current or previous work that generated intense positive or negative emotions. At other moments, respondents, without prompting, offered stories about incidents with emotional significance to them. Stories offer rich research material to both social constructionist and psychoanalytic approaches. From a social constructionist perspective, a story lays bare some of the emotion rules, the scripts and the interactions through which emotions are constructed, displayed and communicated (Czarniawska-Joerges, 1997; Czarniawska-Joerges, 1998; Fineman, 2003). From a psychoanalytic perspective, stories often express unconscious fantasies and wish fulfilments - privileging desire and fantasy as important sources of meaning over factual accuracy (Gabriel, 1991).

Before proceeding to the case material, it is fruitful to reflect upon the ethics of this study. Sonal and Rekha were introduced to me by a contact who was their colleague, thus reducing some of the strangeness or unfamiliarity of the interview setting. Nevertheless, I had anxieties about being an external visitor and asking personal questions about emotions. Reflecting on my anxieties after the fieldwork raised questions about the ethics of research in postcolonial settings. The subsequent analysis and discussion below, however, suggested that interactions in postcolonial spaces, whatever difficulties they generate, need not lead to negative outcomes. On the contrary, they can furnish useful research material and valuable insights in their own right, provided the researcher is willing to disclose some of her/his own emotional 
responses and question them. Thus, Prasad (2014) approaches ethical concerns in postcolonial research, including the emotional awareness of privilege and power, and an ethics of researcher self-care. Disclosing personal reflections in academic outlets about sensitive experiences (as I do here) has risks, and acts of self-protection are critical for the researcher's own emotional wellbeing. When properly analysed, however, these disclosures can furnish valuable insights into the emotional dynamics in sensitive encounters unfolding within fraught postcolonial spaces (e.g. Ulus, 2015) and can be considered postcolonial ethical practices in their own right.

\section{Case studies}

\section{Case study 1: Sonal}

At the beginning of the interview, I explained at length the purpose of my research to Sonal, conveying my interest in India, which dates from early childhood contacts with Indian families and subsequent participation in Indian festivals with college friends. I mentioned my counselling work with Indian students and my overall absorption in India's history. In the hope of creating a shared space and minimising my distance as a researcher, I emphasised my keenness to study emotions and experiences in organizations and countries different from those with which I was directly familiar. While explaining my approach, Sonal warned me that people would give me 'half-baked truths', which reminded me of a view expressed in an earlier interview with Sudhir Kakar ${ }^{5}$ who had cautioned me that Indians would tend to say what they think that I, as a foreign guest, would want to hear. However, once the actual interview with Sonal began, I sensed that she did not see herself as relating half-truths but rather firm

\footnotetext{
${ }^{5}$ I met Professor Sudhir Kakar, India's pre-eminent psychoanalyst, in 2009 for the purpose of explaining this project's psychoanalytic focus in India, and to ask for any recommendations in doing this research.
} 
convictions and incontestable realities. I subsequently realized that, during our encounter, Sonal responded to broad, neutral, nondirective questions in a manner that assumed I was adopting a particular emotional stance. The vehemence of some of her responses can be interpreted through both social constructionist and psychoanalytic considerations. Two extended parts of the interaction exemplifying this pattern will be discussed.

\section{Example 1 with Sonal: Gender}

Early in the interview, I thought it would be interesting and complimentary to ask Sonal about her experiences as a female manager. I have long been interested in the significant presence of Indian women in high managerial and political positions, often in greater proportions than their Western counterparts. It is thus with curious admiration that I sought to learn from Sonal's experiences as a woman with important workplace responsibilities.

Eda: So is there anything specific you would like to say about your experiences [as a female manager]?

Sonal: [Speaking just as I was finishing the question] No it's not [said very firmly] see it depends on the organization, the people you meet. I have worked with various companies I have never seen this... bifurcation, I've never seen [firm repetition of 'never']. Except you do meet people who have that thinking 'Oh she's a female' but largely it's not there $[\ldots]$ it's not, I will not say that this thing is there, that being a female you have a different, no, it's almost equal ....

Eda: OK

Sonal: Rather being a female I can say is to an advantage...in the sense that I don't have to stretch too far. So, my working hours are not that long compared with any other male counterpart... today there is no discrimination between male and female worker.

Eda: OK 
Sonal: I really have not come across.. rather in this organization if I take the example, only the.. females, they sit longer than the male, male counterparts, so, that's there.

Eda: As in... they stay longer in working? [I wanted to clarify what she meant by sitting]

Sonal: Yeah... working hours, they have to stretch working hours than[?] male counterparts.

\section{Eda: Oh OK}

Sonal: So it depends on your position

(Here, there was a shift in the tone of Sonal's voice, possibly revealing her late realization that she hinted at a gender inequality. The result is Sonal returning to another assertion in the next part that there is no difference between men and women at work.)

\section{Eda: Yeah}

Sonal: It really depends on your position, the amount of work you have, it really depends on that, nobody tells you stretch too far, nobody tells you to do things because you're a female. No, nobody does that, so...

What is striking in this exchange is that, in response to an open-ended question about being a female manager, something akin to an emotional storm was released. The question made no mention of discrimination, different working hours, or any other type of inequality, but Sonal's response implied that a judgemental remark or indeed an accusation had been levelled. From a social constructionist perspective, we may argue that Sonal was enacting a performance, which displayed an emotional state of satisfaction with gender at work and perhaps indicated dissatisfaction with having to answer a question that was considered to imply otherwise. Such emotional displays satisfy feeling rules on multiple levels, such as the expectation that people feel happy with a comfortable and just workplace and that they are unwilling to be critical of their employer or their culture to outsiders.

More specific to the Indian context, there appears to be a feeling rule of presenting a positive image of gender relations to foreigners, especially 'white' ones. This is particularly 
likely if Indian employees have come into contact with patronising Western visitors, like consultants, in the past, as illustrated in Muhr's (2012) research into the colonial resonances in encounters between Western consultants and their Eastern clients. As a member of the urban elite with frequent exposure to the West, Sonal must have encountered Orientalist assumptions, not least in her previous job interacting with Westerners, and possibly viewed me as a haughty and presumptuous Western intruder; my anxious attempts to reach out in female solidarity thus may have been interpreted as patronising or insincere, prompting defensive responses. I shall return to a more focused postcolonial analysis in the spirituality discussion below, developing discussion of my own self-analysis as well.

As a white female researcher, Sonal seemed to see me as someone who may harbour negative gender stereotypes about India. In fact, merely asking about gender may have been perceived as a serious transgression. The extract illustrates a clash of emotional expectations between Sonal and me, as if we were operating within different sets of emotion rules. While I approached the question of gender in a spirit of solidarity as a fellow professional woman, impressed by the high achievements of Indian women in traditionally male domains, Sonal's emotion rules constructed me as a 'typical' Western visitor holding stereotypical assumptions and asking awkward questions about sensitive issues. A social constructionist interpretation would approach Sonal's emotional performance in front of a foreign visitor as reflecting India's colonial past and independent present that require presenting India to outsiders as a modern, successful nation that has overcome its colonial past. Some women in this context may not acknowledge to an outsider any experiences of gender injustice or discrimination. One must also consider the emotion rules of the research situation itself. When a stranger or outsider crosses into organizational terrain and begins asking questions, those answering may feel duty bound to 
present their working life in a positive manner. This is especially so if a Western researcher is cast in the part of a colonialist collecting knowledge about the subordinate non-white other, just as his or her predecessors plundered the natural and labour resources of the colonised.

Yet, research situations may spawn very different emotional relations between the foreign researcher and her respondent, governed by very different emotion rules from the ones outlined above. In a discussion of workplace emotions, respondents may discover an opportunity to confess or disclose troubling work matters that they would not disclose to 'insiders', treating the interview exchange, consciously or unconsciously, as a therapeutic space. This kind of emotional encounter characterized my interaction with Rekha, my second interviewee. Positive emotional qualities surfacing during an interview disrupt the conceptualization of researcher-researched interactions in a postcolonial context as doomed to recapitulate oppressive colonial dynamics. Indeed, criticisms of postcolonial approaches include viewing 'othering in relatively bleak terms, disregarding the possibility of creative engagement with the Other' (Gabriel, 2008, 227). In this way, a dyadic process between a Westerner and a non-Westerner may be marked by a wide range of emotional interchanges, which provide a further opportunity for interweaving more than one theoretical perspective - here social constructionist and psychoanalytic ones. With Sonal, these interchanges were marked by anxiety (especially that of the interviewer) and conflicting assumptions, in contrast to the encounter with Rekha, discussed below, which generated an intense experience of emotional solidarity.

These social constructionist considerations about history, culture, and the politics of emotion in research settings provide valuable insights. We can contrast my construction of Sonal's performance as an emotional storm to what she must have regarded as the natural response to a misguided intruder, possibly one who had violated the emotion rules of a polite 
interview exchange. However, the emotional tensions about gender that were conveyed by Sonal have an intensity that may not fully be explained by our differing constructions of one another in the interview context. Indeed, the emotions expressed by Sonal, in the absence of any direct allusion to gender tensions, may call for further probing that draws on psychoanalytic concepts. The feeling rule about pleasing foreigners, while at the same time resisting their supposed presumptions in a postcolonial period, can be seen as the cause of anxiety, which in turn triggers defensive emotional displays. Thus, the interpretation of this interview exchange may be enhanced by entwining insights from both approaches: the social constructionist emphasis on cultural context and feeling rules can be linked with the psychoanalytic examination of internal, private dynamics that occur unconsciously, in reaction to these cultural constructions. In this way, psychoanalysis may explain what happens when emotion rules are seen as violated.

Sonal's emotional performance, therefore, can be analysed with both of these theoretical resources. From a social constructionist view, there is evidence that it 'cracks' (Fineman, 1996, $555)$, in response to a perceived transgression of the rules of the game. From a psychoanalytic perspective, cracks developed because she was not able to use the rules of emotion effectively to defend against the anxiety prompted by the question. Cracks can be found through multiple contradictions in Sonal's responses, wavering from views that gender is not important at work, to acknowledging, albeit fleetingly, that employees are treated in specific ways on the basis of gender. Phrases such as 'almost equal' are especially telling about the tensions raised by this topic that, very surprisingly, aroused deep emotion from Sonal at the beginning of our exchange. Contradictions in interview data should be seen as opening up rich opportunities for analysis. As Muhr and Kirkegaard (2013, 109-110) argue, 'contradictions in interviews are ... not seen as an obstacle, but as the very moments where alternative explanations can take place'. 
To interpret the inconsistencies of Sonal's account further from a social constructionist framework, she was experiencing confusion, being drawn out of her comfort zone into a new encounter (as indeed was I as researcher). Sonal was not yet clear on the precise nature of the emotion rules and expectations for interacting with me (and vice versa). Potter and Wetherell (1987: 50) argue that contradictions in a text, like Sonal's conflicting assertions, indicate shifting constructions of 'a topic according to context'. Sonal's emotions about work and gender as expressed in the text can, therefore, be explained from a social constructionist perspective: she is searching for footing in context, for reliable emotion rules on which to steady herself in an uncertain encounter (which was true of me in my anxious attempts in the interview as well).

From a psychoanalytic standpoint, we can uncover a different line of interpretation about Sonal's emotions by probing the strength of her specific responses to open-ended questions. With regard to my opening question, I thought that Sonal might share some examples of the strengths and challenges of being a woman in a high managerial position. Instead, she brought forth phrases like 'no discrimination' to assert that there is equality at work, raising the question: could the emphatic assertion that specific issues are not issues at all actually be a defence against the anxiety that would be provoked in acknowledging them, especially to a foreign researcher? At this stage it is not possible to offer a definitive answer, but this is a possibility that a psychoanalytic approach to emotions would invite us to examine. We are thus engaging with interpretation by opening up possibilities and rich avenues to explore, made possible through probing unconscious possibilities with psychoanalytic interpretations.

In our interpretation, there is enough tension in the above excerpt to indicate that Sonal may have experienced some gender strains that challenged her desire to convey work harmony to a foreigner. This could have led to some anxiety which, in turn, may have prompted defences, 
unconsciously pushing the possibility of gender discrimination or inequality out of awareness, and conveying a more pleasant emotion about the anxiety-producing topic. From a social constructionist perspective, tension about emotions can be consciously managed. However, the intensity of contradiction and ambivalence in Sonal's responses point to the possibility of unconscious reactions as well. Sonal may have constructed me as harbouring negative stereotypes, which are an example of insults that can trigger unconscious emotions, hence a response of emotional intensity out of proportion to the actual content of the perceived insult itself (Gabriel, 1998a). These uncomfortable emotions, in turn, can elicit the psychological defence of denial.

Reflecting on this excerpt, we are struck by a vacillation between saying that gender does matter in Indian business and that it does not. Bringing together both theoretical perspectives of emotion, this contradiction and the corresponding emotional ambivalence can reflect a variety of possible social tensions that can be processed unconsciously. These include: the clash between what is acceptable to present to a foreign stranger and the reality of one's lived experience, which may include the effects of traditional gender roles intersecting with colonial constructions of masculinity; and strain between the historically strong influence of women in India and the persistence of occasions of oppression in and out of the workplace.

These tensions, indicated by the faltering strength and inconsistency of Sonal's performance, lead to questions such as: why does the performance of specific emotions sometimes fall apart? What happens to emotions when their management is not effective? Where do the emotions then go? Why do very strong emotions about specific issues arise in the absence of conscious stimulation of these topics? The excerpt that follows, from approximately 15 
minutes into the interview, offers some fresh interpretive possibilities and insights into the ways in which Sonal sought to manage her emotions.

\section{Example 2 with Sonal: Spirituality}

Eda: You mentioned religion, that's something I'm very interested in.

(This followed Sonal's earlier mention of different religions in India and her reluctance to define any values as specifically 'Indian').

Is religion and spirituality any part of your workplace?

Sonal: No [firm, quick answer]

Eda: No? OK

Sonal: No [laughter]

Eda: In terms of any rituals, or expectations, or

Sonal: No no no

Eda: $\mathrm{OK}$

Sonal: We've got A, who is a Christian, and I am a Hindu... We don't have any Muslim I guess in Finance Department obviously in the company there are various, but I'm talking about Finance itself, We've got Sikh also, we've got, every religion is there.

(I took a breath to start a new question, then:)

Sonal: Nobody sees the surname now...nobody...Nobody sees what the gender, nobody sees what's the surname or the religion, nobody sees that... [I started a question, but was interrupted]: at least I don't see.

Eda: OK. I visited a university several times before, and they have... a daily, $\operatorname{Havan}^{6}$ [fire], am I saying that properly? They have.. somebody who is doing a proper ritual and prayer, just for the students, is that something that happens here?

Sonal: No no no, nothing, nothing at all, it's purely management... you will not find any one person having majority state in the company. It's a Western influence the religion is not something, nobody who does that... and I am sure [Sonal's emphasis] you will not

\footnotetext{
${ }^{6}$ Religious ritual
} 
find in any of the [Sonal's emphasis] smallest of smallest company... no way you will find anybody imposing any religion.

(Sonal's tone changed during the above comments, especially starting with the 'I am sure' sentence, becoming even more emphatic.)

These responses confirm a pattern. As with the previous example, this extract starts with a broad, open question about a feature at work, this time that of religion and spirituality, prompted by my previous visit to an Indian organization. In pursuing a social constructionist agenda of inquiry, exploring cultural conditioning of emotion, we wanted to learn if, and how, religious and spiritual values, traditions and rituals shape people's emotional experiences at work. The question above was exploratory rather than probing for a specific view, and, as in the earlier case of gender, guided by a curiosity about work meanings.

We can interpret Sonal's responses as again based on certain presumptions about my views. The example given in this excerpt about prayer did not seek to suggest that the prayer was only for students of one religion. Yet, Sonal's responses point to resistance against the idea that one religion would impose its outlook on an organization. Consequently, there was a mismatch between what I asked and Sonal's responses, which seem to assume that I had a hidden agenda. Like the previous example, Sonal appears to be experiencing intense pressures to present a flawless image of the organization to a foreign visitor - the emotionology (Fineman, 2010) of a postcolonial context suggests the politicization of emotion rules about appropriate performances to the outsider. She conveys an excellent organization as one in which people of all backgrounds are represented, and no religious impositions apply.

The social construction of spirituality in India is of further help in framing Sonal's emotional responses of disassociating spiritual concerns from working life. Sonal may have felt 
that I was constructing spirituality on the basis of foreign impressions about the ubiquity of spirituality in Indian daily life, and that I might have made misguided assumptions about spirituality taking over parts of working life as well. The work of Sen (2005) is particularly illuminative of this point. He demonstrates that the West views India so much in spiritual terms that it neglects to understand its extensive intellectual heritage. A source of this perception is the British Empire: 'Magisterial critiques tend to blast the rationalist and humanist aspects of India with the greatest force' to suit the ruling agenda (Sen, 2005, 154). Media reporting of communal conflict may also have coloured Sonal's responses, which, as in the earlier example, seek to negate the presence of any such tensions in her organization. Tensions between religious groups in India are often incited by powerful sectarian groups, as Sen (2005) also argues. Some of these tensions have roots in the tragic legacy of India's colonial past (e.g., see Wolpert, 2006). This past can repeatedly haunt group relations at an unconscious level (see Nandy, 1982, 206) and these relations remain areas of major social concern, heightening sensitivity to interview questions which are found to be awkward and intrusive.

From a social constructionist view, Sonal seeks to defend her construction against what she perceives as a challenge. This exchange evokes Lynch's conceptualization of the social construction of emotions, discussed using the context of India: 'Emotions are essentially appraisals, that is, they are judgments of situations based on cultural beliefs and values... emotions... have functions' (1990, 8-9). Hence, Sonal's responses, analysed in this way, are an outcome of signals that emotion rules have been breached. She has judged that my actions or way of relating have made unfair assumptions, pushing her into a role that she has not asked for, or does not fit her experience. Emotions of resentment or anger may function to signal both to 
Sonal and me this disruption - this inappropriate casting and misunderstanding of the culture of her workplace.

The emotional dynamics of this spirituality exchange are thrown into even sharper relief when the dynamic of power relations are brought into the picture. This interview occurred in an Indian workplace in which the colonial legacy persists, at times in unexpected and insidious ways. As researchers, we occupy privileged positions of power, and the way that our power is perceived is inevitably embodied; that is, my whiteness and outside visitor status may be constructed as a 'looking down' position upon the interviewee. My questioning may have evoked for Sonal the former colonialist, who exerts power in categorizing, controlling and exploiting the other. While I am not white British and do not directly embody the former coloniser, the imperialist policies of the US may be evoked by my American accent and privileged white status, raising a variety of emotional signals about me as a potential transgressor. Yet, the emotional dynamics of my encounter with Sonal cannot be reduced to embodying the colonial oppressor. Work by Gilmore and Kenny (2015) provides nuanced openings to analysing these power dynamics. In the context of reflexivity in ethnography, their work suggests that researchers in new settings may not experience a comfortable power position and may indeed struggle with their field experiences. These complex power dynamics have significant postcolonial implications in our context; the outsider may be constructed as the oppressor or silencer, but the outsider in fact may experience her/his own emotional struggles, in new settings with new relational dynamics and cultural expectations.

Taking up a different line of interpretation from these valuable social constructionist considerations, Sonal's responses suggest that the challenge to her construction is not merely a point of disagreement with the interviewer, but also a cause of anxiety. From a psychoanalytic 
conceptualization (Freud, A., 1966), her performance is characterized by defences, contradictions, assumptions about the hidden meaning of the questions, marked shifts in tone of voice, and above all, repeated phrases like 'no, no, no'. The intensity of these responses indicates that an emotion rule has been transgressed, but it also suggests that this transgression poses a deep psychological threat and has become a cause of inner conflict. Sonal's un-prompted statement that 'nobody' pays attention to surnames, gender or religion, is particularly telling. In India, surnames may give away one's community grouping or caste, which may provide an indicator of historical status in society. From a social constructionist vantage, the assertion 'nobody sees' recapitulates an organizational and social expectation that differences of religion, caste and social background do not affect work. The extra vehemence of the response may be seen as expressing exasperation with a clueless foreigner. Her negations may also be viewed as resistance to being stereotyped by an interviewer who fails to appreciate the varieties of Indian culture, such as secular working environments. Yet, the disjunction between the innocence of the question and the sensitivity with which it is met, the sequence of escalating and pre-emptive negations and the upset emotional tone suggest that something deeper may be at play.

Viewed from a psychoanalytic vantage, 'nobody sees' may very well suggest the exact opposite: that in fact some people at work, even if only a few individuals, do very much 'see', or scrutinize, characteristics like religion, social background, and indeed surname. In many workplaces, such an acknowledgment of the importance of one's caste or status as indicated by surname may very well amount to a taboo. Each society and each organization has its share of anxiety-provoking taboo subjects that evade conscious emotion management and are therefore avoided. Taboo subjects alleviate the anxieties that would be caused by discussing them but create anxieties of their own, especially when the discourse drifts toward the danger zone. From 
a social constructionist perspective, Sonal's pre-emptive mention of 'surnames' can be seen as a warning to the interviewer that she is approaching dangerous or taboo subjects. A psychoanalytic perspective, on the other hand, would approach it as an instance when a first line of psychological defences has been breached (the taboo subject has been alluded to), and a rapid second line of defence residing in emphatic negation is being erected. There is no reason why both explanations may not be appropriate; there is only a difference in emphasis.

Indeed, in an interview I conducted with Salman $\mathrm{Akhtar}^{7}$, eminent Indian psychoanalyst and writer, he noted that 'such vehement denials usually suggest that the mechanism of "negation" - permitting something into consciousness only in its repudiated form - is active'. However, Akhtar added that other variables might have contributed to Sonal's denials as well. Prominent among these are: a distinctly Indian style of speaking, reflected in The Argumentative Indian (Sen, 2005); a resurgence in Indian patriotism; or a misunderstanding of the question's intention.

Misunderstanding the intention of a question assumes added significance in a postcolonial context. Jack and Lorbiecki's (2007) work has demonstrated the historical importance of colonialism for analysing work environments today. Thus, Sonal's vehemence may very well be a response to repeat experiences of condescension in her work, such as her previous Business Process Outsourcing job, in which she indicated that she had received explicit training for interactions with foreign customers. These work experiences may be projected onto 'white' others, me in this instance; I enter her organizational space, fail to connect with her, and appear to commit various transgressions. The study of these postcolonial dynamics brings

\footnotetext{
${ }^{7}$ This interview with Akhtar was conducted as part of the wider study, face to face, for the opportunity to meet with an eminent Indian psychoanalyst in person, and discuss the topic of emotions in India.
} 
together both social constructionism and psychoanalysis, through awareness of the interlocking of social, historical and linguistic factors together with unconscious ones: the anxieties of historical oppression, colonialism's production and reproduction of the 'other', and so on can be unconsciously stimulated, finding expression in unexpected work incidents and later interview exchanges about these experiences and the emotions that mark them.

Before moving on to the second case study, it is important to reflect on my own emotional experience in relation to the interviewee. This self-reflective approach is similar to the work of Kerosuo $(2007,55)$, who analysed her 'emotional engagement in the fieldwork as a researcher in an organizational change workshop', and Blenkinsopp $(2007,255)$, who states that 'my own autobiographical experiences therefore become "data", available for analysis in much the same way interview transcripts might be'. In this paper, our own approach to self-reflection hinges on countertransference, a phenomenon that offers vital pointers to the underlying dynamics of intense social encounters, including research interviews (Stein, 2004). As discussed above, countertransference, a response to transference, refers to the recurrence of powerful emotional patterns, often rooted in earlier relationships.

I found myself taken aback by Sonal's absolute statements which seemed to allow no room for discussion. This led me to feel that I was being kept out of an open dialogue. I continued to search for a way of finding more equivocal, dialogical and nuanced positions, sharing several examples from my own working life. On reflection, I came to realize that attempts to share my own experiences with Sonal were unconsciously guided by my own emotions of hurt in not being allowed access to Sonal's emotional experiences at the workplace, and by my failure to engage in a productive dialogue with her. As argued by Stein (2004), our countertransference provides significant keys to making sense of interview encounters, by 
bringing into consciousness layers of meaning about the relational dynamics of the interviewer and respondent. My own feelings of incredulity and even rejection indicate that there was much more to Sonal's working life than was being disclosed, something not present in what she said but in how she said it. Feeling shut out from a more meaningful and reciprocal encounter, I realized that I might have been naive in hoping to enter her complex organizational experience through the at times artificial means of an interview. Our own emotions, in seeking to overcome what may be deep cultural or social divides, are a valuable source for understanding some of the limits of research interviews.

As suggested earlier however there are times that such divides can readily dissolve during a more open interview encounter, which occurred with Rekha, a manager in the same company as Sonal. Indeed, reflecting upon my exchanges with Rekha, I felt that I became an insider, as discussed by Kerosuo $(2007,66)$ in her work with patients during her project: 'The fieldwork here can, therefore, be characterized as a temporary field with intense relationships that include constant shifting between the positions of outsider and insider'. With Rekha, I was initially an outsider but felt that I was for a time welcomed as an insider, while with Sonal I felt that I remained an outsider. This had implications for our exchanges and my subsequent reflections and analysis of both interactions.

In response to my question about spirituality, Rekha recounted several examples of pujas, or prayer ceremonies, conducted to launch new organizational initiatives. Rekha's candid, matter of fact discussion of spirituality as an important force in the organization, at odds with Sonal's picture of the same organization as devoid of spiritual activity, illustrates the importance of studying varied depictions between accounts, as noted by Potter and Wetherell (1987).

\section{Case study 2: Rekha}


I interviewed Rekha after Sonal. At one point in the interview, when talking about dreams, the following story unfolded:

Eda: Did you have some other kind of nightmare or dream about, either, you know this company, or, good dream, bad dream?

Rekha: Haan ['yes' in Hindi] one more thing [spoken as if she is preparing to share a secret], since it's the recession time, so, many people are being kicked out, to be honest in hard times, many people are being kicked out. Once I got a mail, I was talking to one of my colleagues, she was Manager of Operations, another department at my level. At 2:30 it was 2:30 p.m., I was talking to her, and 4 p.m., I got a mail from her saying 'goodbye'. You won't believe, I was terrified... the same night, I couldn't sleep the whole night with the fear of losing job, for quite some time. Then I realized I do important work in the organization, it cannot be done with me also. I mean it took me days to settle with this.

Eda: Oh my goodness

(This was a response of joining in the storytelling journey to facilitate sharing in the discussion of emotions)

Rekha: Because it used to happen at the senior manager level, at the GM [general manager] level, it didn't affect me, but when the person at my level was kicked out, I was terrified.

Eda: Mm-hmm, I can imagine

Rekha: You won't believe, then it took me some days to settle down. This is the only nightmare.

It is notable that the prompt about dreams or nightmares elicits from Rekha a powerful story about a work incident that generated emotions captured in the metaphor of nightmare. In this story, Rekha's friend is a victim of a cold system that does not have concern for the unexpected and shocking nature of her dismissal. Rekha is also a character in this tragic story, in that the sudden firing had a profoundly unsettling effect upon her as well, raising anxieties about what would happen to her job. Indeed, Rekha's experience demonstrates how the study of 'emotion draws attention to the psychological injuries of working' (Fineman, 2004, 721). My 
responses above, like 'I can imagine', were offered to help create an empathic atmosphere about sensitive topics, and to encourage a storytelling space where Rekha shared her emotional and narrative worlds. We were also struck by how different the relational dynamics were with Rekha compared to Sonal, an observation which provides more nuanced meanings about how 'outsider' - 'insider' dynamics may occur in postcolonial contexts, such as how individuals may respond to emotion rules and anxieties in interaction with one another.

I probed the meaning of Rekha's story further by inviting her to reflect on it:

Eda: How do you settle down in a situation like that? When there's a very difficult situation

(I reflected back Rekha's own words 'settle down' to help connect with her experience and explore how her anxiety was processed.

Rekha: If I feel after all the, what do you say introspection, that I do a value addition, I do not waste my time in the organization, then I feel I cannot be kicked out just like that...

This response can be approached from a woven together perspective of both social constructionism and psychoanalysis. The meaning of Rekha's fears becomes clear through mindfulness of the context in which they occurred: the backdrop of the recession and cold, unexpected dismissals within her organization. Her proximity to threatened dismissal grew when the same-level employee was dismissed, legitimizing the terror that Rekha described - it happened to a colleague at my level, and now it can happen to me. The result is a corresponding change of emotional response from not being affected by firings at other levels, to being terrified. A social constructionist interpretation rightly draws attention to the emotion rule that stipulates terror as a legitimate response to the prospect of dismissal. A psychoanalytic interpretation, however, probes more deeply into the nature of the terror described by Rekha, which is part of a terrifying fantasy that she may be the next manager to be 'kicked out'. This 
results in psychological defences, two of which are clearly apparent: intellectualization and the belief that she is an individual who is 'special'. The former, discussed by Anna Freud (1966), can be applied here as the deployment of essentially cognitive activities, like calculation ('value addition') and logic, to ward off unpleasant emotions. By itself, however, intellectualization may not be enough, given the magnitude of the anxiety, hence the defence of 'specialness', discussed by Yalom $(1998,210)$, comes in.

Referring to death anxieties, Yalom stated that 'we all know that in the basic boundaries of existence we are no different from others. No one denies that at a conscious level. Yet deep, deep down each of us believes...that the rule of mortality applies to others but certainly not to ourselves...' (1998, 210, our emphasis). Rekha is not facing physical death, but it is in the nature of the nightmare to equate violent job loss and exclusion ('kicked out' mentioned four times above) with symbolic death (Stein, 1997, 2001). Thus, Rekha reports a conscious, cognitively worked-through response to the 'terrifying' prospect of dismissal, but behind this intellectualization there may loom an unconscious appeal to 'specialness'. Unconscious processes also helped to explain my and Sonal's interchanges; consciously, our emotions performed functions of evaluating cultural expectations, but unconsciously, we responded to them in ways that were marked by defences.

How does Rekha's account point to the use of a specialness defence? She mentioned higher-level employees losing their jobs; were they all expendable and not adding value? How about the same-level colleague who was dismissed? Were they wasting time? These possibilities are not very likely or logical when considered consciously. Yet, the unconscious but firmly held belief in being 'special' bolsters Rekha's attempt to ward off the distressing emotions of having a job in times of upheaval. Further evidence of Rekha's appeal to her specialness can be found in 
her comment '... and moreover if per se the situation comes [being dismissed], I would request my boss to give me at least one month notice'. This imagined request contrasts sharply with the story of her colleague who was dismissed and told to leave on the same day, something that is likely not consciously realized. Here again Rekha applies her belief that she is different and will be afforded special consideration compared to others who are unceremoniously dismissed. Intellectualization is found in this request as well: it is a response seemingly devoid of emotion to the anxious, frightening possibility of dismissal. Finally, even in the unlikely event of being granted, the request would not prevent dismissal but merely delay or exorcise it. Thus, Rekha's view of specialness can be interpreted as an unconscious mechanism to contend with the terror of possible dismissal, one that simultaneously acknowledges the terror but also disavows it and dismisses it.

\section{Conclusions and future directions}

This paper has examined closely excerpts from two interviews to demonstrate the enhanced understanding of workplace emotions when social constructionist and psychoanalytic accounts are drawn together. Social constructionist accounts illuminate what Craib (1995) calls the 'social scaffolding' which situates emotions - emotions do not occur in a social vacuum but are structured by emotion rules that are deeply embedded in culture and history. In line with theorizing on emotionology (Fineman, 2010, Stearns and Stearns, 1985), the emotional tone of an interview situation involving a Western researcher and Indian respondents is inevitably conditioned by long-standing narratives of privilege and exclusion. Psychoanalysis prompts us to look more deeply into the complexities of felt emotions, marked by unconscious and especially defensive processes. Thus in addressing the concept of emotionology, a psychoanalytic 
perspective would argue that researchers as well as their respondents submit to, but also seek to resist, the emotional roles and experiences into which long-existing narratives have cast them. These defensive stances sometimes backfire and lead to emotional impasses or misunderstandings, while at other times, they make or create the impression of an understanding which is quite superficial. The psychoanalytic perspective calls for a confrontation with one's own emotional defences as a precondition for establishing a genuine understanding of the emotions of the other. As Craib notes, 'the social scaffolding of emotions' does not by itself reveal 'emotional life itself' $(1995,154)$; thus, approaching emotion using psychoanalytic resources provides enriched meanings.

Differences in emphasis and even contradictions between psychoanalysis and social constructionism do not have to become insurmountable obstacles; contrasts between them can be utilized to question, probe and, eventually, sharpen interpretations. The simultaneous use of these two perspectives demonstrates how tightly intertwined and mutually reinforcing social and unconscious factors can be. In the examples that we offered, Rekha's unconscious defences were heightened when she perceived a threat according to her level in the hierarchy, while Sonal's negation was intertwined with pressures of emotional performances in front of a foreigner and perceived transgressions of emotion rules. Rekha's responses were marked by reaching out to me as someone who could recognize her gendered identity as a competent professional; Sonal, by contrast, responded to me as someone seeking to impose an emotional logic on our transaction, which violated her own strongly held beliefs about appropriate emotional engagements.

A crucial feature of this research lies in its contribution to the relatively neglected area of studying workplace emotion in non-Western contexts, and juxtaposing the different emotional assumptions and defences of the researcher to those of the interviewees. Such endeavours 
problematize the assumed sovereign position of the researcher, forcing her or him to confront her or his own defences when encountering the other who presents a very different set of assumptions and defences. In this way, these efforts help to counter or qualify Western models and assumptions. Emotional experiences are critically embedded in the social fabric of a culture, which for India involves a long period of colonial domination - a painful legacy that shapes the nature of work relations, emotion rules, and unconscious dynamics to this day. The cross-cultural applicability of psychoanalysis is therefore part of this study's contribution. Mental mechanisms like defences are found across boundaries, but the conditions shaping them must be understood with sensitivity to the local and historical context.

However, the cultural specificity of work emotions should not obscure the similarities across shared emotional spaces. Work pressures in the face of recessions like those experienced by Rekha, and their powerful impact on emotions at work, transcend national boundaries, although the meaning of job loss may vary from culture to culture. Ambivalence about gender at work, a dynamic brought up by Sonal's extract, is certainly not unique to Eastern contexts. Contradictions between espoused equality and persistent glass ceiling obstacles, inequalities, and stereotypes are routinely experienced by many Western women.

Unconscious activation of former colonial roles can trigger unexpected emotions and unexpected defences. Future research will need to address the prolonged and deep psychological effects of colonialism on workplace emotions, both for the former colonised and colonisers (Nandy, 1982). Currently, both psychoanalytic and social constructionist approaches are in their infancy when engaging with the long-term legacy of colonial relations in work spaces (see for example Prasad, 2003, on the importance of greater engagement with colonial dynamics in management). Yet, both approaches have much to contribute in this regard. Psychoanalysis 
provides a wealth of resources for understanding persistent colonial dynamics that defy rational accounts and counter binary conceptualizations of colonizers and colonized (Bhabha, 2004; Hook, 2008). Social constructionist approaches, for their part, have much to contribute to exploring long-standing emotion rules that persist across radical social and political changes.

In valorising the use of multiple approaches, we end with a sentiment by Akhtar (2005, xviii): 'while it is tempting to focus upon the different [Indian and psychoanalytic] worldviews from which these concepts arise, their courageous juxtaposition might be more heuristically rewarding in the long run'. 


\section{References}

Akhtar, S. ed. 2005. Freud Along the Ganges: Psychoanalytic Reflections on the People and Culture of India. New York: Other Press.

Berger, P.L., and Luckmann, T. 1967. The Social Construction of Reality: A Treatise in the Sociology of Knowledge. London: Penguin Press.

Bhabha, H.K. 2004. The Location of Culture. Oxon: Routledge.

Blenkinsopp, J. 2007. "The Ties that Double Bind Us: Career, Emotion and Narrative Coping in Difficult Working Relationships." Culture and Organization 13 (3): 251-266.

Bolton, S.C. 2005. Emotion Management in the Workplace. Houndmills: Palgrave Macmillan.

Bozionelos, N., and K. Kiamou. 2008. "Emotion work in the Hellenic frontline services environment: How it relates to emotional exhaustion and work attitudes." International Journal of Human Resource Management 19 (6): 1108-1130.

Clarke, S. 2003. "Psychoanalytic sociology and the interpretation of emotion." Journal for the Theory of Social Behaviour 33(2): 145-63.

Cohen, L., and A. El-Sawad. 2007. "Lived experiences of offshoring: An examination of UK and Indian financial service employees' accounts of themselves and one another." Human Relations 60 (8): 1235-1262.

Craib, I. 1995. "Some comments on the sociology of the emotions." Sociology 29 (1): 151-58.

Craib, I. 1997. "Social constructionism as a social psychosis." Sociology-the Journal of the British Sociological Association 31 (1): 1-15.

Cromby, J., and D.J. Nightingale. 1999. "What's wrong with social constructionism?" In Nightingale, D.J., and J. Cromby. eds. Social Constructionist Psychology: A Critical Analysis of Theory and Practice. Buckingham: Open University Press, 1-13.

Czander, W.M. 1993. The Psychodynamics of Work and Organizations: Theory and Application. New York: Guilford Press.

Czarniawska-Joerges, B. 1997. Narrating the Organization: Dramas of Institutional Identity. Chicago: University of Chicago Press.

Czarniawska-Joerges, B. 1998. A Narrative Approach in Organization Studies. Thousand Oaks: Sage Publications. 
Das, D., R. Dharwadkar, and P. Brandes. 2008. "The importance of being 'Indian': Identity centrality and work outcomes in an off-shored call center in India." Human Relations 61 (11): 1499-1530.

Fineman, S. 1996. "Emotion and organizing." In Clegg, S.R., C. Hardy, and W.R. Nord. eds. Handbook of Organization Studies. London: Sage Publications, 543-64.

Fineman, S. 2000. "Emotional arenas revisited." In Fineman, S. ed. Emotion in Organizations. 2nd ed. London: Sage Publications, 1-24.

Fineman, S. 2003. Understanding Emotion at Work. London: Sage Publications.

Fineman, S. 2004. "Getting the measure of emotion - and the cautionary tale of emotional intelligence." Human Relations 57 (6): 719-40.

Fineman, S. 2010. "Emotion in organizations - A critical turn.” In Sieben, B. and Wettergren, A. eds. Emotionalizing Organizations and Organizing Emotions. Houndmills, Basingstoke: Palgrave Macmillan, 23-41.

Freud, A. 1966. The Ego and the Mechanisms of Defense. New York: International Universities Press, Inc.

Frosh, S. 2001. "On reason, discourse, and fantasy. Reasons (to be thankful)." American Imago 58 (3): $627-47$.

Frosh, S., A. Phoenix, and R. Pattman. 2003. "Taking a stand: Using psychoanalysis to explore the positioning of subjects in discourse." British Journal of Social Psychology 42: 39-53.

Gabriel, Y. 1991. "Turning facts into stories and stories into facts - A hermeneutic exploration of organizational folklore." Human Relations 44 (8): 857-75.

Gabriel, Y. 1998a. "An introduction to the social psychology of insults in organizations." Human Relations 51 (11): 1329-54.

Gabriel, Y. 1998b. "Psychoanalytic contributions to the study of the emotional life of organizations.” Administration \& Society 30 (3): 291-314.

Gabriel, Y. 1999. Organizations in Depth: The Psychoanalysis of Organizations. London: Sage Publications.

Gabriel, Y. 2000. Storytelling in Organizations: Facts, Fictions, and Fantasies. Oxford: Oxford University Press.

Gabriel, Y. 2008. Organizing Words: A Critical Thesaurus for Social and Organization Studies. Oxford: Oxford University Press. 
Gabriel, Y. 2009. "Conclusion - Latte capitalism and late capitalism: Reflections on fantasy and care as part of the service triangle." In Korczynski, M., and C. Macdonald. eds. Service Work: Critical Perspectives. New York: Routledge, 175-89.

Gabriel, Y. and D. S. Griffiths. 2002. "Emotion, learning and organizing." The Learning Organization 9 (5): 214-21.

Gilmore, S. and K. Kenny. (2015) "Work-worlds colliding: Self-reflexivity, power and emotion in organizational ethnography." Human Relations 68: 55-78.

Gough, B. 2004. "Psychoanalysis as a resource for understanding emotional ruptures in the text: The case of defensive masculinities." British Journal of Social Psychology 43: 245-67.

Hochschild, A.R. 2003. The Managed Heart: Commercialization of Human Feeling. Berkeley: University of California Press.

Hollway, W., and T. Jefferson. 2000. Doing Qualitative Research Differently: Free Association, Narrative and the Interview Method. London: Sage Publications Ltd.

Hook, D. 2008. "Postcolonial psychoanalysis.” Theory \& Psychology 18 (2): 269-83.

Jack, G., and A. Lorbiecki. (2007). "National identity, globalization and the discursive construction of organizational identity." British Journal of Management 18: S79-S94.

Kakar, S. 1971a. "Authority patterns and subordinate behavior in Indian organizations." Administrative Science Quarterly 16 (3): 298-307.

Kakar, S. 1971b. "Theme of authority in social relations in India." Journal of Social Psychology 84 (1): 93-101.

Kakar, S. 2008. Culture and Psyche: Selected Essays. New Delhi: Oxford University Press.

Kerosuo, H. 2007. "Following My Traces: Exploring the Emotional Engagement with the Research Subject through the Researcher's Artwork." Culture and Organization 13 (1): $55-72$.

Koch, G. 2013. "Border work. Resisting commodification in the workplace (and elsewhere)." Culture and Organization 19(4): 353-67.

Kvale, S. 1999. "The psychoanalytic interview as qualitative research.” Qualitative Inquiry 5 (1): 87-113.

Korczynski, M. 2003. "Communities of coping: Collective emotional labour in service work." Organization 10 (1): 55-79. 
Lynch, OM. 1990 Divine Passions: The Social Construction of Emotion in India. Delhi: Oxford University Press.

Mellahi, K., P. S. Budhwar, and B. Li. 2010. "A study of the relationship between exit, voice, loyalty and neglect and commitment in India." Human Relations 63 (3): 349-369.

Muhr, S. L. 2012. "Strangers in familiar places-using generic spaces in cross-cultural identity work." Culture and Organization 18 (1): 51-68.

Muhr, S. L., and L. Kirkegaard. 2013. "The dream consultant: Productive fantasies at work." Culture and Organization 19 (2): 105-123.

Nandy, A. 1982. "The psychology of colonialism - Sex, age, and ideology in British India." Psychiatry-Interpersonal and Biological Processes 45 (3): 197-218.

Potter, J. and M. Wetherell. 1987. Discourse and Social Psychology: Beyond Attitudes and Behaviour. London: Sage Publications.

Prasad, A. 2003. "The gaze of the other: Postcolonial theory and organizational analysis." In Prasad, A. ed. Postcolonial Theory and Organizational Analysis: A Critical Engagement. New York: Palgrave Macmillan, 3-43.

Prasad, A. 2014. "You can't go home again: And other psychoanalytic lessons from crossing a neo-colonial border." Human Relations 67: 233-257.

Sen, A. 2005. The Argumentative Indian: Writings on Indian History, Culture and Identity. London: Penguin Books.

Sinha, T.C. 1966. "Development of psycho-analysis in India.” International Journal of Psychoanalysis 47: 427-39.

Stearns, P.N. and C. Z. Stearns. 1985. "Emotionology: Clarifying the history of emotions and emotional standards." The American Historical Review 90 (4):813-36.

Stein, H.F. 1997. "Death imagery and the experience of organizational downsizing - Or, is your name on Schindler's List?” Administration \& Society 29(2): 222-47.

Stein, H.F. 2001. Nothing Personal, Just Business: A Guided Journey into Organizational Darkness. Westport, CT: Quorum Books.

Stein H.F. 2004. "Countertransference and organizational knowing: New frontiers and old truths." Free Associations 11 (3): 325-37.

Sullivan, P. 2012. Qualitative Data Analysis: Using a Dialogical Approach. London: SAGE. 
Theodosius, C. 2008. Emotional Labour in Health Care: The Unmanaged Heart of Nursing. Abingdon, Oxon: Routledge.

Ulus, E. 2015. "Workplace emotions in postcolonial spaces: Enduring legacies, ambivalence, and subversion." Organization 22: 890-908.

Vogler, C. 2000. Social identity and emotion: The meeting of psychoanalysis and sociology. Sociological Review 48 (1): 19-42.

Wolpert, S. 2006. Shameful Flight: The Last Years of the British Empire in India. Oxford: Oxford University Press.

Yalom, I.D. 1998. The Yalom Reader: Selections from the Work of a Master Therapist and Storyteller. New York: BasicBooks. 